Asia Pacific Journal of Advanced Business and Social Studies

ISBN (eBook): 9780994365675 | ISSN : 2205-6033

Year: 2018 , Volume: 4, Issue: 2

\title{
WEB DESIGN OPTIMIZATION: FOR ONLINE STORES
}

\author{
Seungjoo Lee \\ The State University of New York (SUNY) Korea, Incheon, Republic of Korea \\ Corresponding Email: seungjoo.lee@stonybrook.edu
}

\begin{abstract}
The purpose of this study is web design optimization, finding the most optimized user interface (UI) for online stores. From previous researches, we believe that consumers' perceived values of the products they shop, and their actual purchase intentions are significantly affected by web design factors - colour of the background, placement of the product image on its product page, length of the page, and much more (Kim et al., 2003). To extend such study, we conducted a survey research on whether and how different categories of products should be placed on different positions of the web page (right vs. left; top vs. down; scroll vs. button-click page turn) to maximize customers' perceived product values and to increase their purchases. To conduct the survey, we used both online and offline survey channels (but with the same survey questionnaire and design). To look for and control possible cross-cultural variations in people's preferences over this online product placement and web design, we also collected each respondent's cultural demographic backgrounds - nationalities, languages, ages, majors. The survey consists of three different studies, all 2 by 2 models and responses on 7-point Likert scales. We have conducted a series of surveys on undergraduate and graduate students from various cultural and demographic backgrounds and have statistically analysed this set of data using Analysis of Variance (ANOVA) and logistic regressions. The survey was conducted three times, from 2016 to 2017. The results have supported majority of our hypothesis: as one, the perceived price of a product is higher when displayed on the right, and this significantly increases their purchase intentions. Such positive relationship is mediated by the percentage difference between the perceived price and the actual price of that product. We believe this study has made additional contributions on this area of academic researches - product placement and purchase intentions and that the findings from here can provide some meaningful implications to the practitioners in improving their product pages to enhance online consumers' shopping experience and increase sales.
\end{abstract}

Keywords: Web Design Optimization, Product Placement, Online Marketing, Purchase Intentions.

\section{Introduction}

Since the European Organization for Nuclear Research (CERN) publicly announced its free sharing in December 1993, the World Wide Web (WWW) has experienced exponential growth with an accompany of rapid adoptions by common users worldwide. According to UN International Telecommunications Unions (2013), an approximate of 7.1billion of the world's population is using the Internet, representing the global Internet penetration rates of $31 \%$ and $77 \%$ in the developing and in the developed worlds, respectively. Recently, one of the rising key functions of the Internet lies in electronic commerce (e-commerce), an industry in which buying 
and selling of products are conducted via Internet, online networks. This includes online transactions such as online banking and online retail stores.

A Nielson Global Consumer Report (2010) conducted a survey on more than 27,00o Internet users over 55 markets worldwide and revealed that about $81 \%$ responded that they had had online shopping experiences and $66 \%$ had made purchase decisions; however, virtually half of the respondents demonstrated little intention of purchasing online in near future. This is a stark contrast to any mythical views over rapid growth of online stores, where rolling lists of customer reviews posted on product pages and record-high views and clicks; the increase in actual purchase decisions can best be deemed laggards over those faceless, virtual stores. The research question of this paper has started from this ironic gap between raw observations and the reported statistics.

Marketing scholars, in line with dynamic, evolving market environments, have studied relevant research topics such as online (vs. offline) consumer behaviours, novel online marketing tools (e.g., Social Networking Services (SNS), firm-oriented Word-of-Mouth), and performance of online stores (vs. offline stores) and are continuously extending their research interests. Researchers and industry managers, on their own distinct contributions, have investigated the roles of "Web design" in affecting consumer perceptions and purchase intentions, but have paid little attention to the optimization of visual alignment of design factors constituting a product page. Therefore, this paper mainly aims to investigate ways of optimizing web design through experiments observing consumer perceptions and purchase intentions in the context of a product page in online retail stores.

\section{Theoretical Background}

\section{1 Web Design}

Earlier studies on the website design have mostly focused on design factors based primarily on designers' intuition and sentience; any naïve ignorance to users' cognitions and thinking mechanisms met with failures to satiate their needs. (Bieber \& Isakowitz, 1995) While they made contributions by generating some useful practical implications in designing web pages, the studies soon raised questions and faced limitations as they failed to understand cognitive aspects of consumers and thus, their guidelines lacked coherence and suffered cognitive overhead at best (i.e., an excessive use of multimedia can kill information storage of users (Conklin, 1987).

Dalala et al, (2000) studied web design with a focus on consumers' cognition in the context of "home" pages. They conducted a 2 (Page Design: Cognitive vs. non-Cognitive) by 2 (Presentation Mode: Text- vs. Graphic-based) between-subjects experiment and found that cognitively-designed home pages resulted in better and faster comprehension and higher perceived understanding of viewers. This provides a critical implication that it is not an option, but rather a must to reflect customer thoughts, how they perceive and how much and well they understand when designing an online store's web page. In addition to this, studies such as Simon (2001) and Yoon's (2002) have suggested significant integral relationships between user satisfaction \&perception and web designs.

Kim et al, (2003) conducted three experiments to investigate and quantify relationships between 13 pre-defined key emotional dimensions experienced by online consumers and web design factors, such as colour and shape of different components (menu, border, etc.) in "home" pages. Their findings gave practical guidelines in designing web pages in accordance with target customer groups by evoking intended emotions, such as hopefulness. 
Meanwhile, there have been studies done cross-culturally in efforts to figure out cultural differences in favoured web designs and achieve better customization in online display. Dianne et al (2004), for one, observed and analysed 30 municipal web sites in three countries, Japan, Germany, and United States over various design factors they found meaningful in the pre-test, including symbols, layout, colour, tool of communication, and language. Their findings provided supports for their initial hypotheses predicting significant differences across the three cultures in preferred web designs, ranging from colour and shape of banners to navigation and search capabilities.

Faiola et al., (2011) studied differences on how Americans and Koreans evaluated the aesthetics of web home pages. These studies concluded that though American and Korean participants used emotional adjectives with similar meanings and hence, demonstrated significant emotive coherence, the fact that they had used different adjectives to describe aesthetic dimensions of web pages suggested a gap exists between the two cultures' aesthetical yardsticks.

Deborah and Elizabeth (2004) made another distinct approach by developing an assessment scale named Website Preference Scale (WSPS) based on a 2- vs. 3-Dimensional environment psychological study done by Rachel and Stephen Kaplan. Here, they incorporated overall impression and likelihood of revisit as meaningful variables in understanding user cognition. Furthermore, they suggested simplicity matters the most in web design, accompanied by appropriate text size, aversion of contextual overload, and easy-to-understand layout.

Jaeki and Fatemeh (2005) adopted the Belief Reinforcement Model (BRM) from the field of social psychology to investigate how various categories of web-design elements reinforce customer beliefs and thus, positively influence online shoppers' attitudes and behaviours. They found that web-design elements (of promotion and service, in particular) play significant roles in improving customer attitudes and increasing their purchase intention in a path that went usually from beliefs about price and service to attitude, then finally to purchase intention.

Research on web design has evolved continuously over almost two decades and thus, topics discussed are countless, ranging from cognitive approach to developing new scales of evaluation. However, there have been few studies on how placement of visual information, specifically, will influence customer perceptions and purchase intentions. Also, studies to date have paid little attention to the lower-level, product pages in online stores; nonetheless, they are important as they provide critical source of information affecting purchase decision of shoppers. The current study is aimed to make an incremental contribution to by focusing specifically on product pages, paying particular attentions to find visually optimal web design (or alignment) in accordance with consumer cognition.

\section{2Visual Information and its Spatial Position}

\subsection{Visual Information \& its Spatial Position.}

A stream of earlier studies relevant is about visual attention, in which researchers investigated visual recognition and attentional selection consisting in making perceptual categorizations of colour, shape and location (Claus, 1990). Reportedly, location of visual information was revealed to have a significant effect in the function of exposure duration and probability correct. Also, a "foreknowledge" (i.e., having the initial information on where the visual information is located without moving eyes) of spatial position of a target facilitates capturing agents' attentions, mainly due to the sense of familiarity and predictability.

A later study by Gerald (1997) incorporated visual attention as a mediator in the causal relationship of visual stimulus (e.g., colour, size of advertising) resulting in choice behaviour in the context of telephone directories. Specifically, a hypothesis that expected significant difference between ads with vs. without graphics (visual information) was supported. While the Asia Pacific Institute of Advanced Research (APIAR)

DOI : 10.25275/apjabssv4i2bus11 
study observed and analysed diverse aspects of ads - size, boldness of texts within, etc. - and how they affected searchers' attentional movements and subsequent choice behaviours, it shows few speculations over layouts and spatial positions of design factors within or of ads. Breugelmans and Katia (2011) discussed how three different types of product displays, First-screen display, Aisle display, and Shelf tag display vary in their effects on boosting product/brand sales. Their findings listed the three displays in order of effectiveness. Nonetheless, the authors didn't provide sound theoretical explanations for such discreteness.

According to Xiaoyan and Barbara (2009), location of a product image on a package façade influences how consumers perceive heaviness of the product and evaluate the package. The study suggests the bottom and right sides are perceived the "heavier" locations while the top and left sides the "lighter".

Extending from the extant literature, hence, the current study poses following research questions: How does spatial location (right vs. left and top vs. bottom) of a product image within a product web page affect customer's perception and purchase intention in the context of online stores? Thus, we hypothesize,

$H_{1}$ : Perceived price of a product is cheaper when displayed on the left; that said, consumers will expect the product more expensive when displayed on the right.

$\mathrm{H}_{2}$ : Perceived quality of a product is lower when displayed on the left; that said, consumers will view the product having higher quality when displayed on the right.

$H_{3}$ : (a) Consumers will show higher purchase intentions to a product when it is displayed on the right, compared with when on the left, and (b) this relationship is mediated by perceived price and quality of the product.

$\mathrm{H}_{4}$ : For product categories which consumers expect heaviness, putting product image at the bottom of the page will increase (a) product evaluation, and (b) purchase intention.

$H_{5}:$ For product categories which consumers expect lightness, putting product image at the top of the page will increase (a) product evaluation, and (b) purchase intention.

These, along with the findings from the study of Xiaoyan and Barbara (2009), are also developed based on people's conventional wisdom about right vs. left. As these self-explanatory terms indicate, "right" is often regarded superior over "left" in traditional and conservative societies. This study is distinct from the extant literature in that the location effects of product image in offline contexts are incorporated into product displays of online stores, measuring their impacts on consumer perceptions. Also, while Xiaoyan and Barbara (2009) observed package evaluation of consumers as influenced results, this study is aimed at investigating how the product image location affects consumers' evaluations of the product and subsequent purchase intention.

\section{3Paging vs. Scrolling}

Dubbed "the flood of information", the virtual space of the Internet is enormously vast, not delimited spatially and temporally. Many online shoppers have been annoyed by information overload and from their experiences, they've learned to selectively taking the information they wanted by skipping and/or scrolling.

In large, a web page with contents going beyond a single screen view has two ways of layout, "paging" (discrete information) and "scrolling" (continuous information). Here, another set of research questions arose: Of paging and scrolling, which can alleviate consumers' feeling of information overload? Also, should optimal location of product image (top vs. bottom) differ between the two types of page layout, paging and scrolling?

Asia Pacific Institute of Advanced Research (APIAR)

DOI : 10.25275/apjabssv4i2bus11 
Peytchev et al. (2006) conducted laboratory experiments on the effects of paging vs. scrolling on respondents' task completion, perception \& evaluation, and staying duration in the context of online survey. The findings indicated respondents under the "scrolling" condition significantly longer staying duration within the content page and more positive evaluation on the task. This implies scrolling, compared to paging, would perform better in alleviating perceived information overload. In contrast, however, another study by Michael et al, (2002) conducted experiments in the context of web browsing \& searching tasks and found their respondents preferred paging over scrolling, possibly due to less loading time.

So far, the discussed literature suggests unsettled controversy in understanding user perception on paging vs. scrolling. One thing which is clear is that in all studies concerned, the variable of paging vs. scrolling was found to have significant effects on user perception and behaviour. Since online shopping, is similar to the web browsing \& searching activities, we hypothesize,

$H_{6}:$ A product page designed to flip pages (vs. to scroll) will make consumers (a) stay longer with the product page, (b) read and remember the product information better, (c) give more positive product evaluation, and (d) have higher purchase intention.

Since paging is free from information overload, location of product image (top vs. bottom) will not have any significant impact on customer perceptions and purchase intention; in case of scrolling, however, feeling of information overload can be affected by location of product image and have subsequent impacts on consumer perceptions and purchase intention. Thus, we hypothesize,

$H_{7}$ : Given a scrolling product page, locating the product image at the top (vs. bottom) will make consumers (a) stay longer with the product page, (b) read and remember the product information better, (c) give more positive product evaluation, and (d) have higher purchase intention.

This paper is directed to make an incremental contribution by incorporating established studies on spatial location of visual information (right vs. left, top vs. bottom) and web page layout (paging vs. scrolling) into online retail product page contexts, investigating their direct and indirect impacts on product evaluation and purchase intention. The remaining of the paper will be organized as follows. In Study 1 and 2, hypotheses positing impacts of spatial locations of product images will be tested. In Study 3, hypotheses on the main effects of web page layout and moderating effects of product image are going to be tested. Lastly, the general discussion on overall studies and implications will conclude the article.

\section{Study 1: Right vs. Left}

To test the hypotheses from $\mathrm{H}_{1}$ to $\mathrm{H}_{3}$, an experiment using the online survey tool, Qualtrics.com was conducted with undergraduate and graduate students in State University of New York campus in Korea. The data collection lasted for about 2 weeks during the May of 2016, with the total respondents of 83. The total valid responses were 83. The sample consisted of 52 male undergraduate students and 31 female undergraduate students, aged 22.1 on average.

\section{1 Design and Procedure}

Study 1 consists of a between-subject design with two product-image-location conditions. Upon starting, each survey taker is randomly assigned to the "right" vs. "left" group. The online survey welcomes the survey participants with a short greeting. The first short block of the survey asks basic demographic questions - gender, age, and primary language. The second block of the survey asks a series of questions about each respondent's online shopping experience. The third block asks a couple of questions on his/her purchase intention on the product category 'a classic shirt'. The fourth block opens with a picture of a gender-specified classic shirt with no brand or Asia Pacific Institute of Advanced Research (APIAR)

DOI : 10.25275/apjabssv4i2bus11 
any other value-estimable identifications, asking a series of questions on his/her perceptions on the product, such as willingness-to-pay, purchase intention, and perceived money value. The product picture displayed here was randomized with the right- and the left-aligned.(see Figure 1(a) and (b)). Most of the questions were expected to be answered with the multiple choices designed in the 7-point Likert scales.

To make sure all the responses included in the data set are valid and meaningful, the survey concludes with a simple question to check whether the participants have attended to the product image is posed in addition: "In the previous part of this survey, which side was the classic shirt displayed?”.

Figure 1(a): An Example of a Product image at right (male)

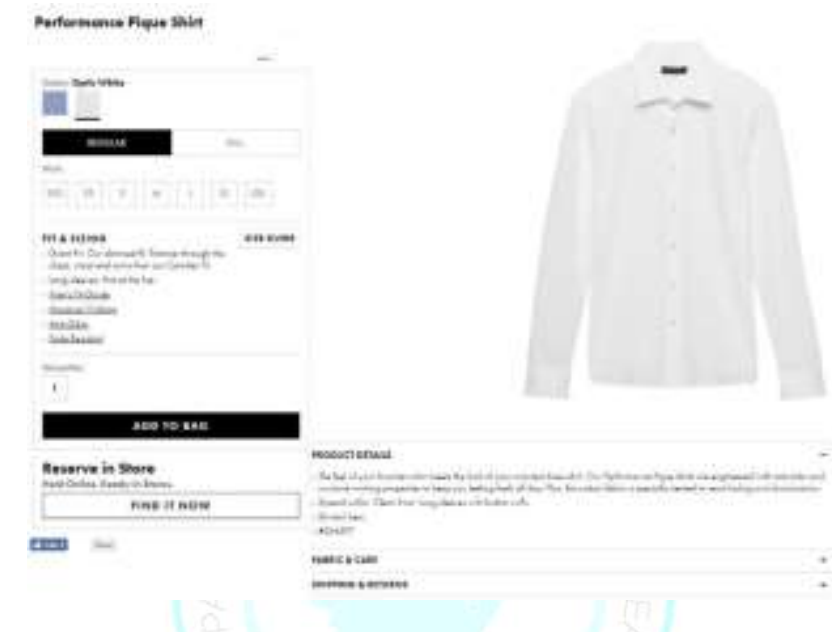

Figure 1(b): An Example of a Product image at left (female)

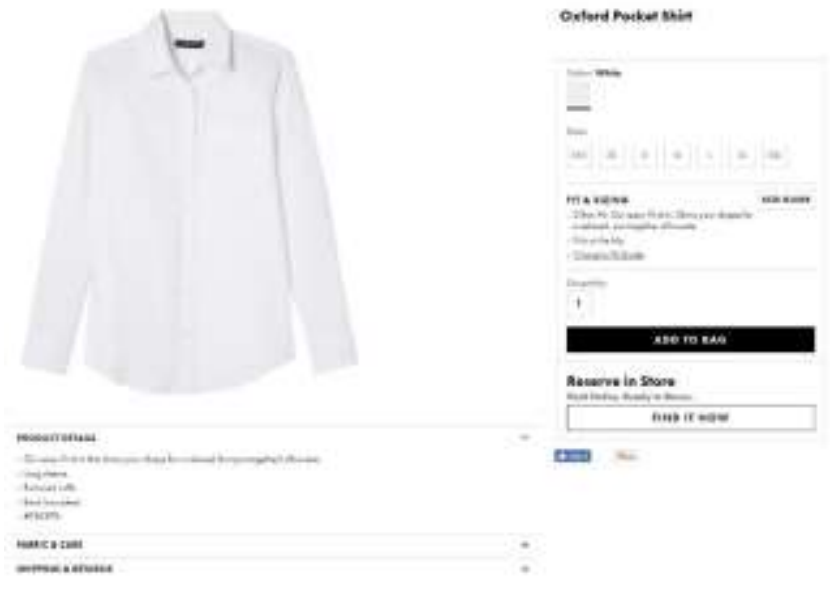

\section{2 Result and Discussion}

The literature and common sense tell people's usual perception regards "left" as inferior, while "right" as superior. And our related set of hypotheses ( $\mathrm{H}_{1}$ to $\left.\mathrm{H}_{3}\right)$ developed earlier well reflect this. Hence, we expect to see all three hypotheses supported. 
First, the result of Analysis of Variance (ANOVA) shows that the product is perceived of higher price and better quality when its image is located at the "Right" side of the product page, in comparison with when located at the "Left" side. Furthermore, respondents exposed to the product page with the "Right" product image are expected to demonstrate higher purchase intentions on average. These proves the statistical significance of the main effects of Study 1 (H1, $\mathrm{H} 2$, and $\mathrm{H}_{3} \mathrm{a}$ ), the impact of image location's "Right" vs. "Left" on product perceptions and purchase intention (Figure 4).

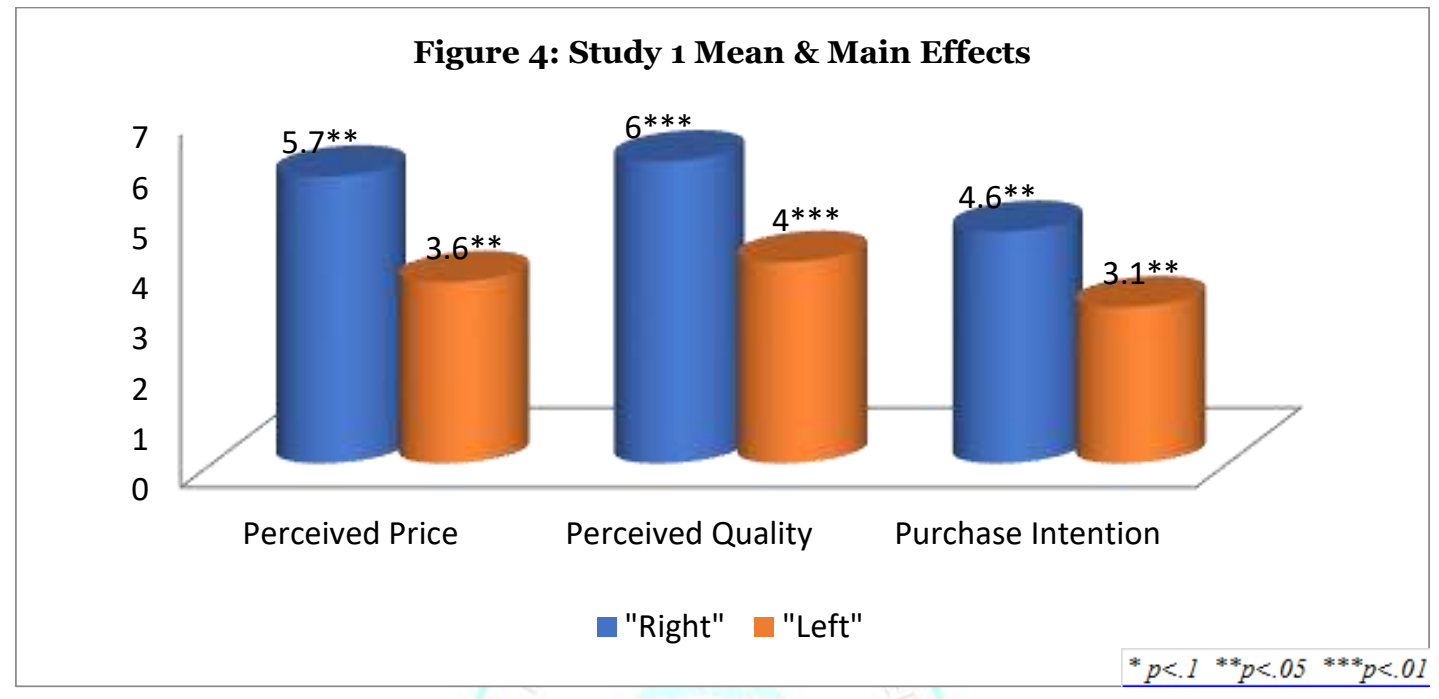

Next, to find a supportive ground for $\mathrm{H}_{3}$ b hypothesizing mediating roles of perceived price and quality of the product on purchase intention, three separate linear regressions were modeled and run: (1) product image location to purchase intention, (2) perceived product price and quality to purchase intention, and (3) both product image location and perceived price and quality to purchase intention (multiple regression with the former as a controlling variable). The result showed some significant and positive partial mediation effects by perceived quality.

Figure 5(a). Mediating Effect: Perceived Quality

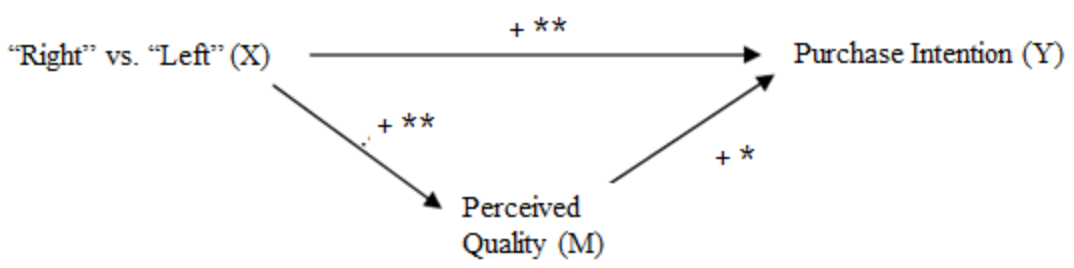

Figure 5(b). Mediating Effect: Perceived Price

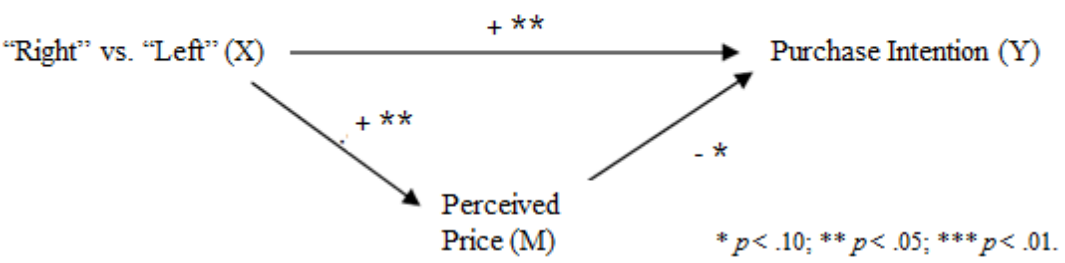

Asia Pacific Institute of Advanced Research (APIAR)

DOI : 10.25275/apjabssv4i2bus11 
In terms of price, since our sample is comprised mostly by students who generally are financially restrained and are price-sensitive, higher perceived price are shown to have significant, but negative partial mediation effect (Figure 5(a) and 5(b)).

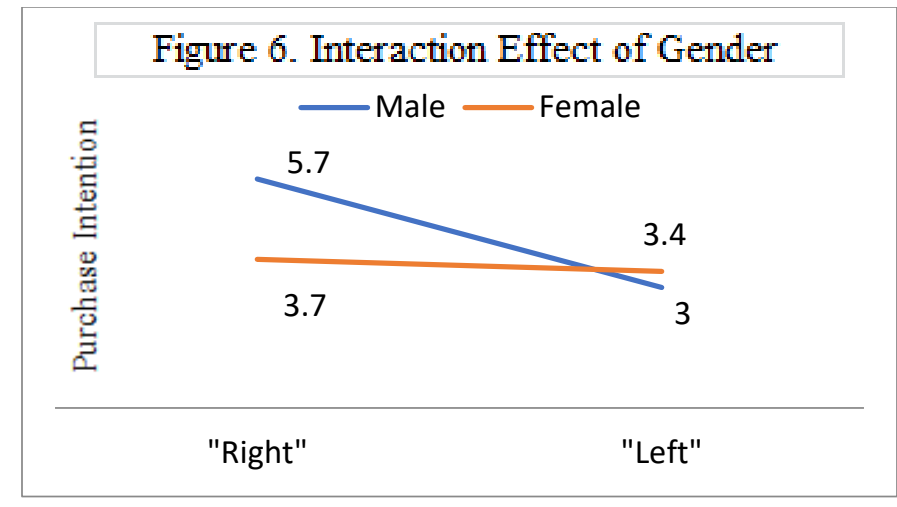

Considering the product being a gender-biased product targeting specifically men, we controlled for gender effects in all our models, including as a fixed effect. Male participants, in the survey, appeared more engaged in shopping and buying the product (men's classic shirt) than their counterparts(Figure 6). We believe that this reflects real-world situations in large. While females have more chances to go offline shopping with their friends and colleagues and would choose to try out before buying clothing, male customers are more likely to shop along, on their own, and mostly online where products are cheaper and more various in kinds.

\section{Study 2: Top vs. Bottom}

To test Hypotheses 4 and 5, an experiment using the online survey tool, Qualtrics.com was conducted with undergraduate and graduate students in State University of New York campus in Korea. The data collection lasted for about 2 weeks during the month of May,2016, with the total respondents of 103. The total valid responses were 99 (1 didn't finish the survey). The sample consisted of 60 male undergraduate students and 39 female undergraduate students, aged 21.8 on average.

\subsection{Design and Procedure}

Study 2 consists of a 2(product type: antique sofa vs. ultra-book laptop) by 2(product image location: top vs. bottom) between-subjects design. An antique sofa is a type of product often expected and preferred to be heavy due to the materials it is made with (e.g., wood and leather). An ultra-book laptop, in contrast, is a kind of product intended to be portable and easy-to-carry with slim appearance and light weight. Thus, it is expected to be 'the lighter, the better'.

The general layout of the survey questions is akin to that conducted for Study 1. The only changed parts were the deletion of gender-specified difurcation of product pictures and that consumer perceptions on two different product categories with different general market expectations for higher value and price were asked.

Figure 2(a) and (b): Sofa displayed at the (a) top and (b) bottom of the page

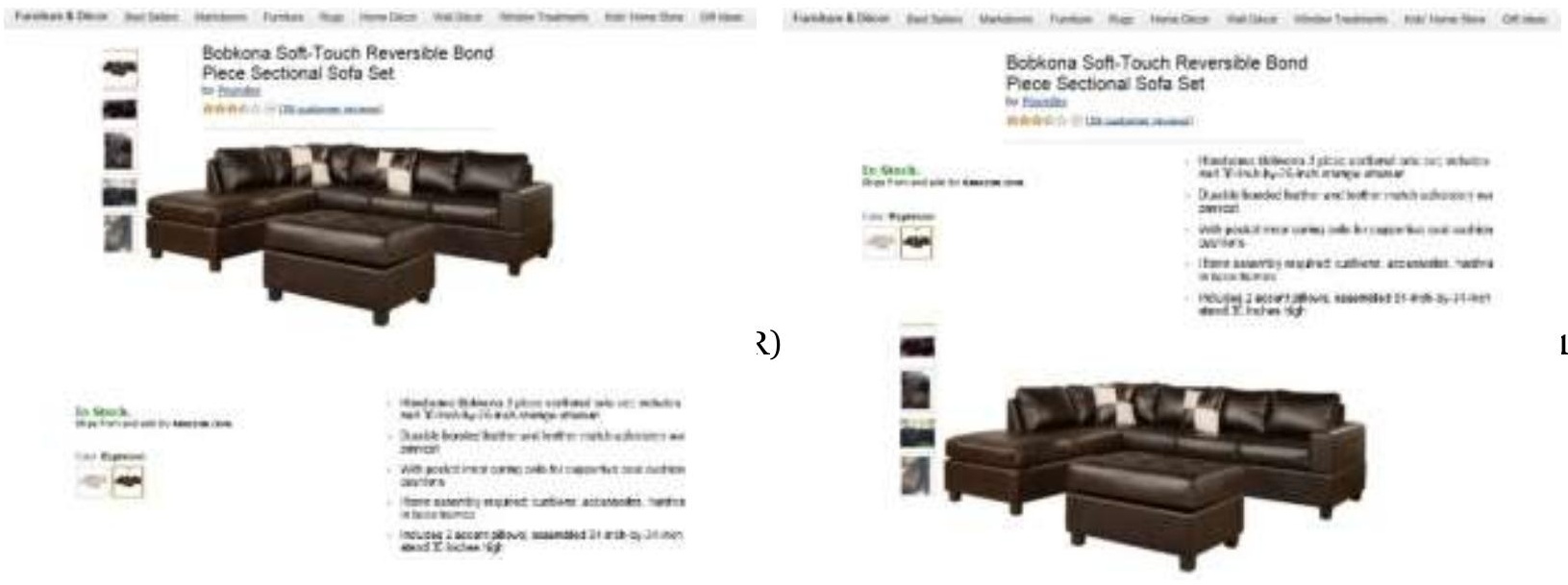


Figure 3(a) and (b): Laptop displayed at the (a)top and (b)bottom of the page

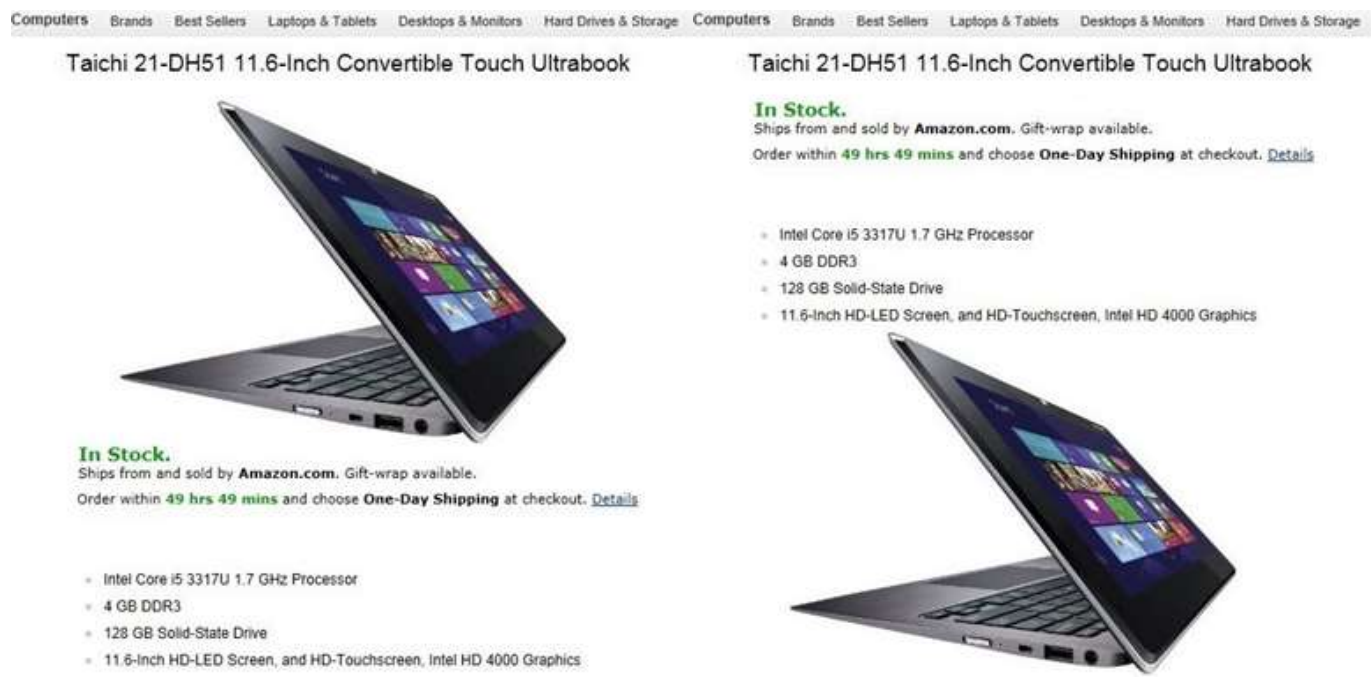

As a manipulation check, asked a question based on the product exposed in the product page to make sure a participant's perceived heaviness of a product type and his/her preference for that product's heaviness match properly. Also, to rule out possible invalid responses made without looking at the product page, a couple of simple questions on the location of the product image (top or bottom) and the product type (sofa or laptop) they saw were asked.

\subsection{Result and Discussion}

\section{Manipulation Check.}

A pair of questions were asked to choose expected and preferred heaviness of the products they shopped: (1) "Do you expect a typical antique sofa/ultra-book laptop to be heavy or light?" (2) "Do you prefer a heavy or light antique sofa/ultra-book laptop? Respondents were given three choices, "Heavy", "Light", and "Not sure". With regard to the furniture category's antique sofa, more than $70 \%$ of the respondents chose "Heavy". As of the electric appliance category's ultrabook laptop, an overwhelming majority (over nine folds) of the respondents chose "Light" as the desirable characteristic (see Figure 7). Thus, our manipulation check succeeded.

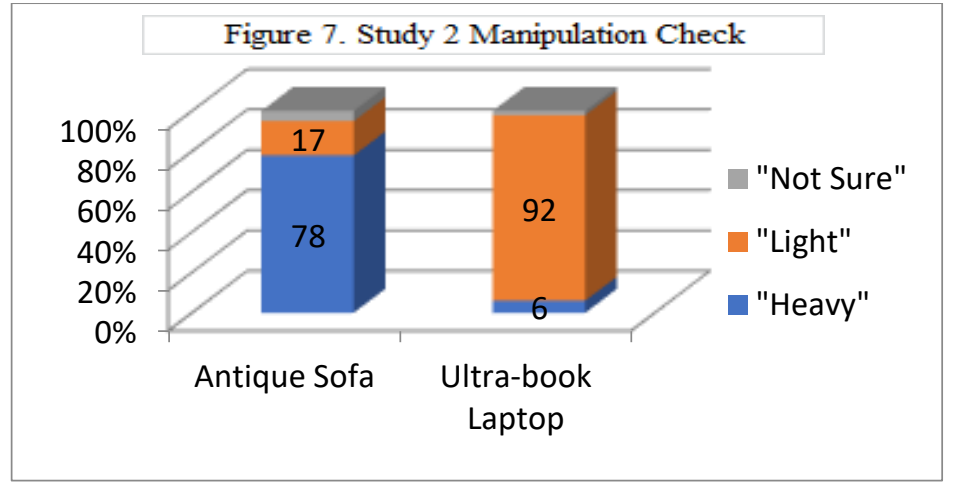


The result of Analysis of Variance demonstrated significant supports for the expected interaction effects of product image location: "top" vs. "bottom" and product type: "heavy (sofa)" vs. "light (laptop)" on product evaluation and purchase intention posited in $\mathrm{H}_{4}$ and $\mathrm{H}_{5}$. As Figures 8(a) and (b) show, the respondents expressed significantly more positive product evaluation and higher purchase intention in case of "bottom" (vs. "top") product image for the "heavy" product and vice versa for the "light" product.

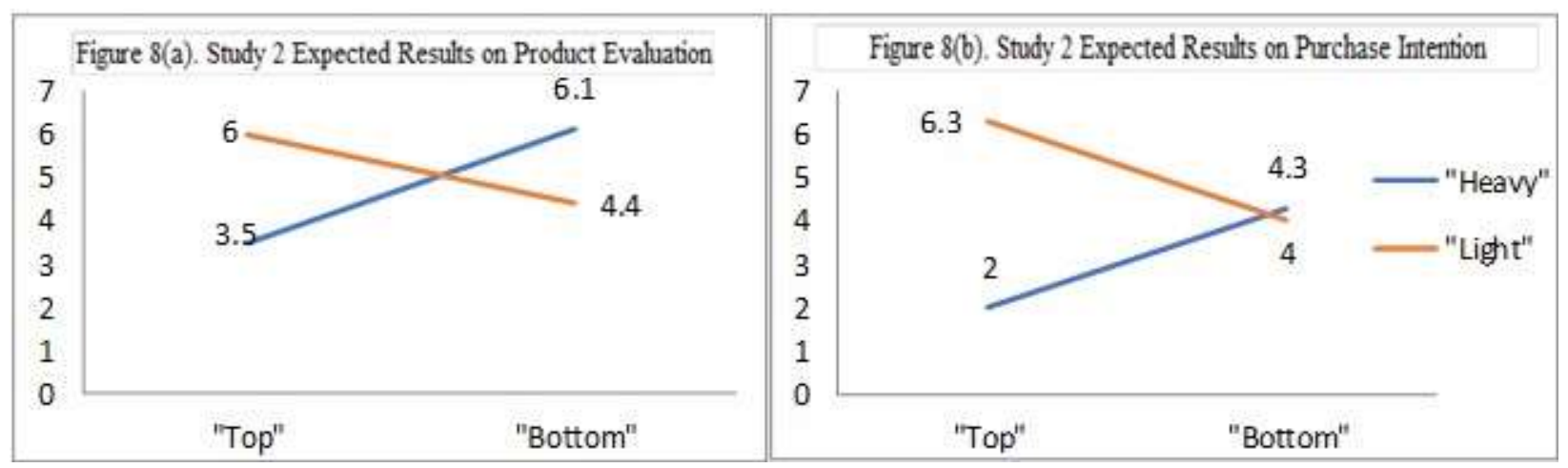

Because an antique sofa is not usually included in young students' shopping list and is not a product typically shopped online, the interaction effect was marginally significant. Furthermore, online shopping and purchasing experience positively moderated purchase intention. We believe such significant moderating effect may have derived from the young respondents' familiarity to the web interface and context lowering any barrier and hesitations, resulting in more positive attitudes towards the products in making purchase decisions. Lastly, contrasting to our original hypothesis that gender should be a significant factor in understanding diverted purchase intentions on an up-to-date laptop, female and male resondents in our survey have revealed no significant distincitons. Initially, we expected males to be more captivated by the newest, portable gadgets and thus would express higher purchase intention and willingness-topay, in comparison to their counterparts. This may be true in many real-world environments. However, this wasn't the rule in our survey taken in the Korea campus of Stony Brook University because, assumably, the students were all engineering-majored, having fundamental and indepth interests on IT technology and applied gadgets.

\section{Paging vs. Scrolling}

Hypotheses 6 and 7 were tested during Study 1 and Study 2. That is, each of the respondents participated in Study 1 and Study 2 were randomly assigned to either the "Paging" or the "Scrolling" version of the survey. In the "Paging" version of the surveys, each block of the survey (Study 1 and Study 2 had 5 and 6 blocks, respectively) were on a different page. Once a respondent finishes answering the questions in a block and presses the "next" at the right bottom of the screen, he/she would be directed to the next block page. This procedure would continue till the end of the survey. In the "Scrolling" version of the surveys, all blocks compositing each survey are displayed in a single page. A respondent of a survey may move from one block to another by scrolling down the page instead of clicking the "next" button.

\subsection{Result and Discussion}

Asia Pacific Institute of Advanced Research (APIAR)

DOI : 10.25275/apjabssv4i2bus11 
In Study 3, we expected to see the main effects of the page layout: paging vs. scrolling and the interaction effects of the page layout: paging vs. scrolling and the product image location: right vs. left.

On one hand, Analysis of Variance was conducted to test the main effects of the page layout: paging vs. scrolling on four interested dependent variables, (a) duration of staying in the product page, (b) memory on product information, (c) product evaluation, and (d) purchase intention. Here, the duration of a participant staying in the product page (looking at the product picture)was measured automatically by creating statement variables with Qualtrics.com within the survey. Specifically, the "paging" product page with discontinuous information layoutalleviated viewers' perceived information overload and subsequent negative feelings, resulting in customers (a) staying longer in the product page, (b) have better information on the product after browsing, (c) evaluating the product more positively, and (d) expressing higher purchase intention.

On another hand, Analysis of Variance was conducted to test the interaction effects of the product page layout and the product image location on the four dependent variables identical as above. From this test and analysis, the hypothesis that in case of a scrolling product page, in which information overload is greater, putting the product image at the top (vs. bottom) will make consumers (a) stay longer with the product page, (b) read and remember the product information better, (c) give more positive product evaluation, and (d) have higher purchase intention was proved(see Figure 9(a) through (d)). Meanwhile, the interaction effect of the product image location was insignificant in case of "paging". We believe such contrasting result derived as the "paging"survey with divided sections of questions caused little annoyance from information overload.

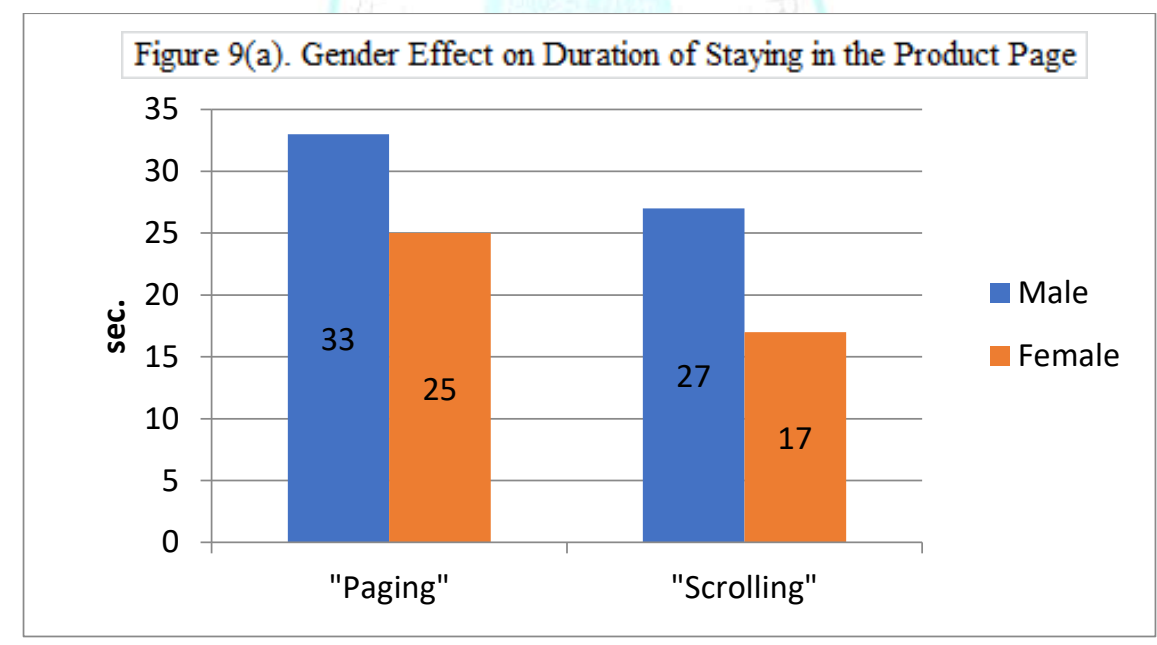




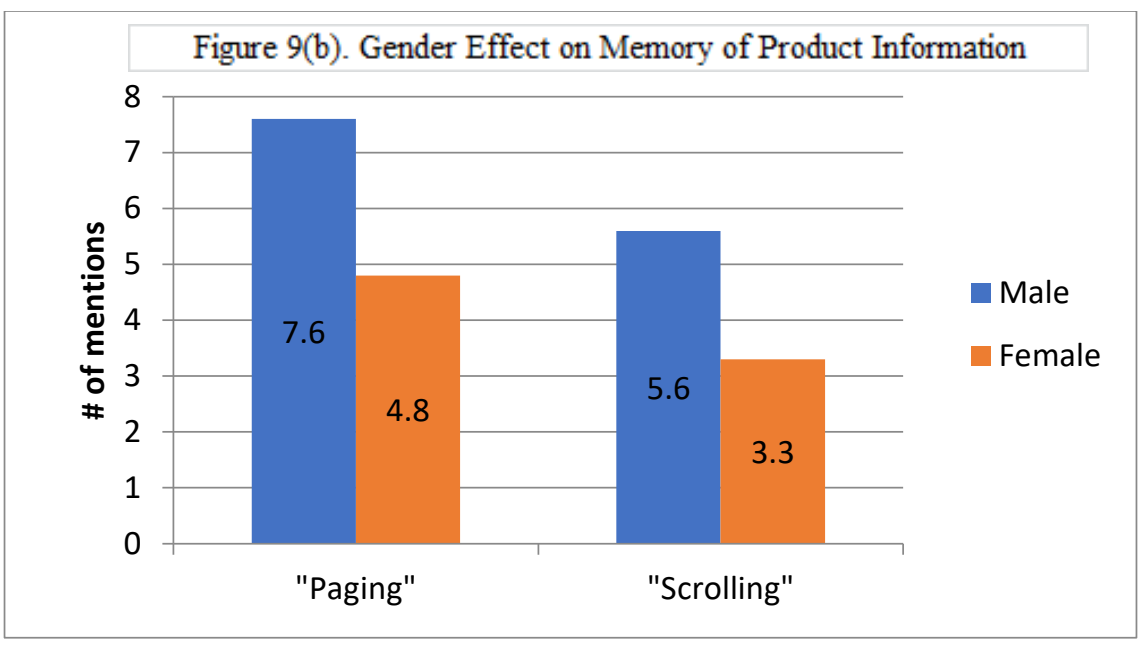

6. General Discussion and Conclusion

\subsection{Summary}

A series of two online surveys have been conducted in the form of experiments in Study 1 and 2, and we found that most of our initially posited hypotheses are supported. In particular, the two dimensions of product image location within a single-paged product page, "right" vs. "left" and "top" vs. "bottom", and the product page layout: "paging" vs. "scrolling" were shown to have direct and main effects on product perceptions/evaluation and purchase intention. Taking a step further, in case of "right" vs. "left", product evaluation was found to have a significant mediation effect as well. In case of purchase intention, moreover, the analysis proved significant moderating effects from respondents' previous shopping experience due to feeling of familiarity to the online shopping interface.

\subsection{Future Research Suggestions and Limitations}

Though our study is believed to have made incremental contributions by studying the direct and indirect impacts of both the product image location and the product page layout on product evaluation and purchase intentions in online shopping contexts, there are limitations to acknowledge and areas for future research development. One of the major limitations lies in narrowness and a potential biased nature of the products used. More specifically, the impacts of "right" vs. "left" and "top" vs. "bottom" can differ in their valence depending on product categories. For example, luxury goods may receive higher purchase intentions when perceived pricier while basics goods may not. Also, for some product categories that have many substitutes, people will be less careful to their qualities and prices and thus their mediation effects might not be significant. As an extension, this study can further continue in another novel context, the mobile world. Given much smaller screen and physical relative inconvenience, will the product image location and the page layout matter?

Moreover, while we tried to add cross-cultural aspect into our study, the culture-related variables we studied through our surveys didn't reveal any significant impacts to consumer behavioural differences. This may lead to our future research for additional improvements to answer one of the key research questions asked in this paper.

\subsection{Implications}

On one hand, the findings from this research can bring some practical and easy-to-apply implications for managers of online stores or of businesses that have Internet-friendly 
customers to better optimize their web designs. For one, simple modifications in product image location can easily improve customer's perceptions and evaluations, resulting in more consumption.

On another hand, this study is expected to give some meaningful academic contributions and implications in that even within the online retails context, the product image location matter significantly and its main effect as well as interaction effects with the page layout has direct and significant impacts on how consumers evaluate the product itself and their buying decision, respectively. This reconfirms the importance of incorporating cognitive aspects of users/ customers into the web design to succeed and demonstrates the external environmental factors (web design factors) can significantly affect internal product assessments (product evaluation and purchase intentions.)

\section{Acknowledgements:}

This research was supported by the MSIT (Ministry of Science and ICT), Korea, under the ICT Consilience Creative Program (IITP-2017-Ro346-16-1007) supervised by the IITP (Institute for Information \& Communications Technology Promotion

This research was done in affiliation with State University of New York (SUNY) Korea. 


\section{Rerefrences}

i. Anon, 2018. World Wide Web. Wikipedia.[Online] Available at: http://en.wikipedia.org/wiki/World_Wide_Web.

ii. Bernard, M., Baker, R. and Fernandez, M., 2002. Paging vs. scrolling: Looking for the best way to present search results. Usability News, 4(1).

iii. Bieber, M. and Isakowitz, T., 1995. Designing hypermedia applications. Communications of the $A C M, 38(8)$, pp.26-29.

iv. Breugelmans, E. and Campo, K., 2011. Effectiveness of in-store displays in a virtual store environment. Journal of retailing, 87(1), pp.75-89.

v. Bundesen, C., 1990. A theory of visual attention. Psychological review, 97(4), p.523.

vi. Conklin, J., 1987. Hypertext: An Introduction and Survev.J.Computer, 20(9), pp.17-41.

vii. Cyr, D. and Trevor-Smith, H., 2004. Localization of Web design: An empirical comparison of German, Japanese, and United States Web site characteristics. Journal of the Association for Information Science and Technology, 55(13), pp.1199-1208.

viii. $\quad$ Dalal, N.P., Quible, Z. and Wyatt, K., 2000. Cognitive design of home pages: an experimental study of comprehension on the World Wide Web. Information Processing \& Management, 36(4), pp.607-621.

ix. Deng, X. and Kahn, B.E., 2009. Is your product on the right side? The "location effect" on perceived product heaviness and package evaluation. Journal of Marketing Research, 46(6), pp.725-738.

x. $\quad$ Faiola, A., Ho, C.C., Tarrant, M.D. and MacDorman, K.F., 2011. The aesthetic dimensions of US and South Korean responses to web home pages: A cross-cultural comparison. Intl. Journal of HumanComputer Interaction, 27(2), pp.131-150.

xi. $\quad$ Statistics, I.T.U., 2011. Key ICT indicators for developed and developing countries and the world (totals and penetration rates). [Online] Available at: $h t t p: / / w w w$. itu. int/ITUD/ict/statistics/at_glance/KeyTelecom. html. [Accessed 2012]

xii. Kim, J., Lee, J. and Choi, D., 2003. Designing emotionally evocative homepages: an empirical study of the quantitative relations between design factors and emotional dimensions. International Journal of Human-Computer Studies, 59(6), pp.899-940.

xiii. Lohse, G.L., 1997. Consumer eye movement patterns on yellow pages advertising. Journal of Advertising, 26(1), pp.61-73.

xiv. Nielsen, J., 2010. Global trends in online shopping. A Nielsen Global Consumer Report, pp.1-10.

xv. $\quad$ Peytchev, A., Couper, M.P., McCabe, S.E. and Crawford, S.D., 2006. Web survey design: Paging versus scrolling. International Journal of Public Opinion Quarterly, 70(4), pp.596-607.

xvi. $\quad$ Rosen, D.E. and Purinton, E., 2004. Website design: Viewing the web as a cognitive landscape. Journal of Business Research, 57(7), pp.787-794.

xvii. Simon, S.J., 2000. The impact of culture and gender on web sites: an empirical study. ACM SIGMIS Database: The Database for Advances in Information Systems, 32(1), pp.18-37.

xviii. $\quad$ Song, J. and Zahedi, F.M., 2005. A theoretical approach to web design in e-commerce: a belief reinforcement model. Management Science, 51(8), pp.1219-1235.

xix. Yoon, S.J., 2002. The antecedents and consequences of trust in online-purchase decisions. Journal of Interactive Marketing, 16(2), pp.47-63.

Asia Pacific Institute of Advanced Research (APIAR)

DOI : 10.25275/apjabssv4i2bus11 